\title{
A Matching Model of Endogenous Growth and Underground Firms
}

Gaetano Lisi and Maurizio Pugno

ISSN: 2031-4892

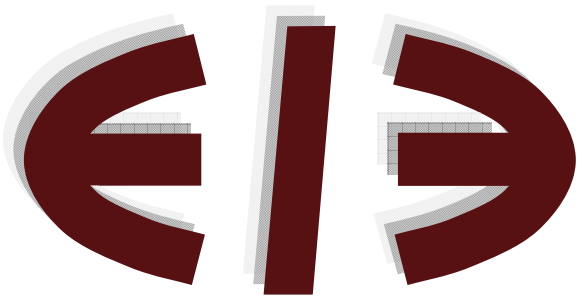

EERI

Economics and Econometrics Research Institute Avenue de Beaulieu 1160 Brussels

Belgium

Tel: +3222988491

Fax: +322 2988490

www.eeri.eu 


\title{
A Matching Model of Endogenous Growth and Underground Firms
}

\author{
GAETANO LISI \& MAURIZIO PUGNO ${ }^{\bullet}$ \\ University of Cassino and CreaM, Italy
}

January 2012

\begin{abstract}
A matching model will explain both unemployment and economic growth by considering the underground sector and human capital. Three problems can thus be simultaneously accounted for: $(i)$ the persistence of the underground sector, (ii) the ambiguous relationships between underground employment and unemployment, and (iii) between growth and unemployment. Key assumptions are that entrepreneurial ability is heterogeneous, skill accumulation determines productivity growth, job-seekers choose whether to invest in education. The conclusions are that the least able entrepreneurs, whose number is endogenous, set up underground firms, employ unskilled labour, and do not contribute to growth. If the monitoring rate is sufficiently low, underground employment alleviates unemployment, but the economy grows at lower rates.
\end{abstract}

JEL classification: E26, J6, J24, L26

Keywords: matching models, endogenous growth, underground economy, entrepreneurship, unemployment

\footnotetext{
- Corresponding author. Department of Economic Sciences and CreaM, University of Cassino, via S. Angelo, I-03043 Cassino (FR), Italy. Tel.: +39 0776 2994702, fax +39 0776 2994834; e-mail: m.pugno@unicas.it.
} 


\section{INTRODUCTION}

The study of the underground economy that adopts matching-type models is not new in the economic literature. Two aims are usually pursued: solving the 'shadow puzzle', i.e. the persistence of the underground economy in a variety of contexts and times (Boeri and Garibaldi, 2002, 2006); highlighting the ambiguous relationship between underground employment and unemployment (Bouev, 2002, 2005; Boeri and Garibaldi, 2002, 2006; Kolm and Larsen, 2003, 2010; Fugazza and Jacques, 2004; Bosch and Esteban-Pretel, 2009; Albrecht et al., 2009).

The study of endogenous economic growth that also adopts matching-type models was initiated by Pissarides' (1990) book, and by Aghion and Howitt (1994), so that the issue of the relationship between growth and unemployment has been both raised and addressed with new analytical tools (Laing et al., 1995; Aghion and Howitt, 1998; Mortensen and Pissarides, 1998; Pissarides, 2000; Mortensen, 2005). In fact, different authors obtain different results concerning the sign of the correlation between growth and unemployment, both across countries and across long periods of time in the same country (Aghion and Howitt, 1994; Bean and Pissarides, 1993; Caballero, 1993; Hoon and Phelps, 1997; Muscatelli and Tirelli, 2001). This ambiguity has been explained on the basis of theoretical assumptions about technological progress and the interest rate (see the next section). ${ }^{1}$

However, as far as we are aware, no study has attempted to deal with the three issues at the same time, i.e. (i) the persistence of underground economy, also called the "shadow puzzle', (ii) the ambiguous relationship between the underground employment and unemployment, (iii) the ambiguous relationship between growth and unemployment. This paper makes such an attempt by developing a new matching model with the following key assumptions and extensions. First, individuals are heterogeneous in their entrepreneurial ability, and they can use it to run either a regular firm or an underground firm, which has smaller entry costs, taxes, and wages, but also lower productivity. These assumptions, which are empirically well-founded (La Porta and Shleifer 2008), make it possible to find an interior equilibrium where both sectors survive, thereby adopting Lucas's (1978) approach of heterogeneous talent allocation, which has been subsequently developed by Baumol (1990), Rauch (1991), and van Praag and Cramer (2001). In this equilibrium, individuals with an

\footnotetext{
${ }^{1}$ From an empirical point of view, results seem less ambiguous, since the capitalization effect dominates (see Pissarides and Vallanti, 2004, 2007). However, Tripier (2006) argues that both views are relevant since positive and negative co-movements can coexist: in the long run, the unemployment rate and labour productivity growth co-move negatively because of the real rigidity of the labour market, they co-move positively over the business cycle because of the nominal rigidity of the goods market.
} 
unprofitable level of entrepreneurial ability seek jobs as employees; individuals with just sufficient ability open vacancies in the underground sector, and the ablest individuals open vacancies in the regular sector. This solution of the 'shadow puzzle' is new and general.

Another key assumption of our model states that regular firms employ skilled labour, while underground firms employ unskilled labour. This assumption is supported by a variety of evidence (Agénor and Aizenman, 1999; Boeri and Garibaldi, 2002, 2006; Bosch and Esteban-Pretel, 2009; Cimoli, Primi and Pugno, 2006; Kolm and Larsen, 2010). In the individual's choice setting, this assumption leads to the further analytical postulate that individuals who search for jobs as employees have already chosen whether or not to invest in education and to become skilled before entering the labour market. Empirical support is provided by the fact that employment in the underground sector and the education level within countries appear to be negatively correlated (Albrecht et. al., 2009; Cappariello and Zizza, 2009).

A further key assumption of our model receives rather usual support in the literature about the role of human capital in endogenous growth (Romer, 1986, 1988, 1989; Lucas, 1988; Rebelo, 1991; Stokey, 1991), as recently surveyed by Savvides and Stengos (2009). Specifically, the assumption states that the education level determines productivity growth (Laing et al., 1995) by producing externalities also in favour of the underground sector. Since the education level is higher in the regular sector, the size of this sector contributes to explaining economic growth. Therefore, the ultimate engine of economic growth is "good matching" between the ablest entrepreneurs and the most educated workers.

This conclusion is interesting for the debate on the role of the underground economy in economic development, and on the policy implications (de Soto, 1989; Johnson et al., 2000; Friedman et al., 2000; Farrell, 2004; Carillo and Pugno, 2004; Banerjee and Duflo, 2005; Cimoli, Primi and Pugno, 2006). In particular, our theoretical conclusion accounts for La Porta and Shleifer's (2008) empirical finding that growth needs those firms which are most productive, and which hence cannot be informal.

On the basis of these assumptions, our model aids understanding of not only the shadow puzzle (issue $(i)$ ), but also the ambiguous relationships between underground employment and unemployment (issue (ii)), and between growth and unemployment (issues (iii)). Issue (ii) has arisen in the literature because of an ambiguity in the results. According to Bouev's $(2002,2005)$ matching model, scaling down the underground sector may lead to a decrease in unemployment, whereas, according to Boeri and Garibaldi's (2002, 2006) matching model, attempts to reduce shadow employment will result in higher open 
unemployment. Issue (iii) has been effectively synthesised by Mortensen (2005), who shows that the correlation between average growth and average unemployment over the past ten years across 29 European countries is essentially zero.

By considering that the economy includes underground firms, which benefit from evading taxes and from lower wages, but are burdened by backward techniques and by the risk of being discovered as unregistered and destroyed according to a monitoring rate, our model yields the following conclusion about issue (ii). The proportion of underground employment is positively related with the unemployment rate if the monitoring rate is sufficiently high, whereas, conversely, the proportion of underground employment is negatively related with the unemployment rate if the monitoring rate is sufficiently low. Since the proportion of underground employment negatively contributes to economic growth, the conclusion about issue (iii) follows. Economic growth is negatively related with unemployment if the monitoring rate is sufficiently high, whereas economic growth is positively related with unemployment if the monitoring rate is sufficiently low.

The empirical plausibility of these conclusions can be shown by scatter diagrams on the growth/unemployment axes vis-à-vis Mortensen's (2005) synthesis, which eventually brings us to issue (iii). The groups of countries with the highest monitoring rate (captured by the 'rule of law' index), such as the EU non-transition countries, exhibit a negative correlation (Fig. 1 and Tab.1). The groups of countries with the lowest monitoring rate, such as the EU transition countries and the Latin American countries, exhibit a positive, though less close, correlation (see Figs 1-2 and Tabs 1-2). ${ }^{2}$

\section{========== Figs. 1-2 and Tabs. 1-2 about here =========}

The rest of the paper is organised as follows: section 1 briefly reviews the literature on growth and unemployment in the matching framework; section 2 presents the model with underground sector and finds the steady-state solutions; section 3 extends the model to endogenous investment in education and finds the steady-growth solutions; while section 4 concludes with some remarks on policy implications. The appendices set out the relevant proofs and mathematical details.

\footnotetext{
${ }^{2}$ The correlation coefficient between the growth rate and the unemployment rate for the group of EU nontransition countries is -0.30 if they report a high 'rule of law' (above 88), and -0.17 for the same group irrespective of the 'rule of law'. The correlation coefficient for the group of EU transition countries is -0.13 if the outlier Poland is included but 0.30 if it is excluded. The correlation coefficient for the group of Latin American countries is 0.43 if Chile, which records a high index of 'rule of law' (88), is excluded, and 0.39 if Chile is included.
} 


\section{A BRIEF Literature REVIEW}

Before the recent papers of search and matching theory, economic growth was usually analysed in a framework without unemployment. This was an important shortcoming in the neoclassical literature, as acknowledged by Solow himself (1988), but it was justified by the mere cyclical nature of unemployment. The influential papers of Aghion and Howitt (1994, 1998), Mortensen and Pissarides (1998) and Pissarides (2000), enable us to study growth and unemployment in the same framework, linking the neoclassical growth theory (Solow, 1956) with the theory of the natural rate of unemployment (Friedman, 1968; Phelps, 1968). It has thus been recognised that unemployment has also a structural nature which persists over the business cycle.

The analysis of both growth and unemployment has concentrated on technological progress. As shown in Pissarides (2000), innovation can be introduced into search and matching models in two ways. First, this can be done by assuming that technological progress is disembodied, meaning that labour productivity in both old and new jobs grows at the exogenous rate of technological progress. Second, on assuming Schumpeter's notion of "creative destruction", technological progress is embodied in new jobs, meaning that labour productivity in old jobs does not grow.

As in the standard neoclassical model (Solow model), technological progress is disembodied in the sense that both old and new jobs benefit from higher labour productivity without it being necessary to replace their capital stock. ${ }^{3}$ In the disembodied technological progress, the higher the technological progress, the lower is the discount rate. Hence, the present-discounted profits are higher and firms open more vacancies. This is the so-called "capitalization effect", which implies both higher growth and a lower steady-state unemployment rate (Pissarides, 2000).

When technological progress is embodied in new jobs, growth can come about through job destruction and the creation of new and more productive jobs, owing to the need to replace the capital stock. In the case of embodied technological progress, the rate of job destruction is endogenous, and it is higher at faster rates of growth. Hence, faster technological progress is associated with a higher steady-state unemployment rate (Aghion and Howitt, 1994, 1998).

According to Mortensen and Pissarides (1998), these opposite results found in the literature on growth and unemployment can be interpreted within a more general model in

\footnotetext{
${ }^{3}$ This is the only form of technological progress that is consistent with a balanced-growth path.
} 
which the direction of the effect of productivity growth on unemployment depends only on the size of the updating cost. Formally, Mortensen and Pissarides (1998) find a critical renovation cost such that faster growth decreases unemployment if the updating cost is below this critical value, and it increases unemployment if the updating cost is above the critical cost.

Finally, according to Mortensen (2005), there is no clear prediction about how the unemployment rate and the aggregate growth rate should be correlated across countries or across time, and the net effect of growth on unemployment is unclear. Indeed, in Mortensen's model two opposite effects are at work: the negative effect of creative destruction on market tightness, since a more rapid rate of job destruction reduces the value of firm and entry, and the positive relationship between the destruction rate and labour market tightness implied by the steady-state equilibrium condition, namely the equilibrium between job destruction and job creation.

The present paper takes another look at the structural link between growth and unemployment by recognising that the economy usually includes an underground sector, which is backward and less attractive for educated people with respect to the regular sector.

The fact that education plays a key role in human capital formation and economic growth has been widely studied in the endogenous growth literature (Savvides and Stengos, 2009) since the pioneering works by Romer (1986) and Lucas (1988). In particular, Laing et al. (1995) use a matching framework to analyze the 'long-run' endogenous growth rate in an economy in which 'short-run' labour market frictions and investment in education are important for the economic growth process. In particular, the economic growth rate depends crucially on the human capital growth rate. They find that a higher contact rate of workers with vacancies leads to a higher rate of growth of human capital and a lower level of unemployment.

However, no study has attempted to link the human capital-economic growth nexus to unemployment through the economy's sectoral composition.

\section{THE MODEL WITH UNDERGROUND SECTOR AND UNEMPLOYMENT}

\subsection{The matching framework}

The paper proposes a general model of equilibrium unemployment (Mortensen and Pissarides, 1994; Pissarides, 2000), where numerous firms competitively produce a homogeneous product, but adopt different institutional and technological set-ups. They may be registered, and therefore pay a production tax and adopt a relatively advanced technology; 
or they may not be registered, and therefore evade taxes and adopt a less efficient technology. Hence non-registered firms form the underground or shadow sector of the economy, which is illegal because of the process employed, not because of the good being produced.

As is usual in matching-type models (Pissarides, 2000; Petrongolo and Pissarides, 2001), the meeting of vacant jobs and unemployed workers is regulated by an aggregate matching function $m_{i}=m\left(v_{i}, u\right)$, where $i \in\{r, s\}$ denotes the sector ( $r=$ regular, $s=$ shadow), $v_{i}$ measures the vacancies in the sector, and $u$ measures the unemployed (who are the only job-seekers). By assumption, the matching function is non-negative, increasing and concave in both arguments and performs constant returns to scale, so that the job-finding rate, $g\left(\theta_{i}\right)=m\left(v_{i}, u\right) / u=m\left(\theta_{i}, 1\right)$, is positive, increasing and concave in the so-called market tightness, $\theta_{i}=v_{i} / u$. Analogously, the rate at which vacancies are filled, $f\left(\theta_{i}\right)=m\left(v_{i}, u\right) / v_{i}=m\left(1, \theta_{i}^{-1}\right)$, is a positive, decreasing and convex function in $\theta_{i}$. Further, the Inada-type conditions hold: $\quad \lim _{\theta_{i} \rightarrow 0} f\left(\theta_{i}\right)=\lim _{\theta_{i} \rightarrow \infty} g\left(\theta_{i}\right)=\infty$; $\lim _{\theta_{i} \rightarrow \infty} f\left(\theta_{i}\right)=\lim _{\theta_{i} \rightarrow 0} g\left(\theta_{i}\right)=0.4$

The Bellman equations for each sector (specified to find infinite horizon steady-state solutions) are the following: ${ }^{5}$

$$
\begin{array}{ll}
r V_{s}=-c_{s}+f\left(\theta_{s}\right)\left[J_{s}-V_{s}\right] & r V_{r}=-c_{r}+f\left(\theta_{r}\right)\left[J_{r}-V_{r}\right] \\
r J_{s}=x y_{s}-w_{s}+(\delta+\rho)\left[V_{s}-J_{s}\right] & r J_{r}=x y_{r}(h)-w_{r}-\tau+\delta\left[V_{r}-J_{r}\right] \\
r W_{s}=w_{s}+(\delta+\rho)\left[U_{s}-W_{s}\right] & r W_{r}=w_{r}+\delta\left[U_{r}-W_{r}\right] \\
r U_{s}=z+g\left(\theta_{s}\right)\left[W_{s}-U_{s}\right] & r U_{r}=z+g\left(\theta_{r}\right)\left[W_{r}-U_{r}\right]
\end{array}
$$

where $V_{i}$ is the value of a vacancy; $J_{i}$ is the value of a filled job; $U_{i}$ is the value for seeking a job; $W_{i}$ is the value for being employed; $r$ is the instantaneous discount rate; $c_{i}$ is the start-up cost; $x_{i}$ is entrepreneurial ability; $y_{i}$ is labour productivity, which depends - in the official sector - on human capital of workers, $h ; w_{i}$ is the wage rate; $\tau$ is an exogenous production tax; $\rho$ is the monitoring rate, i.e. the exogenous instantaneous probability of a firm being discovered (and destroyed) as unregistered; $\delta$ is the exogenous destruction rate; $z$ is the opportunity cost of employment. The parameters $r, c_{i}, y_{s}, \tau, \rho, \delta$, and $z$ are always considered as positive and exogenous. For the time being, $h$ is assumed as a parameter, but it will be treated as an endogenous variable in section 3.

\footnotetext{
${ }^{4}$ The matching functions of the two sectors may be different, but evidence is lacking in this regard.

${ }^{5}$ Time is continuous, and individuals are risk neutral, live infinitely, and discount the future.
} 
Empirical evidence suggests that underground employment is one of low productivity jobs (Agénor and Aizenman, 1999; Boeri and Garibaldi, 2002, 2006; Cimoli, Primi and Pugno, 2006; Bosch and Esteban-Pretel, 2009). Therefore, our first key assumption is the following.

Assumption 1. Labour productivity is much lower in the underground sector with respect to the regular sector: $y_{s}<<y_{r}{ }^{6}$

Wages are unique within the two sectors. In the underground sector the wage rate is assumed to be the outcome of the bargaining between one of the workers who seek job in this sector, and the entrepreneur endowed with the minimum level of ability $x_{\min }$, who turns out to be an irregular entrepreneur (see subsection 2.2). Formally:

$$
w_{s}=\arg \max \left\{\left(W_{s}-U_{s}\right)^{\beta} \cdot\left(J_{s}-V_{s}\right)^{1-\beta}\right\} \Rightarrow\left(W_{s}-U_{s}\right)=\frac{\beta}{(1-\beta)} \cdot\left(J_{s}-V_{s}\right)
$$

where the parameter $\beta \in(0,1)$ is the worker's bargaining power. Simple manipulations thus yield:

$$
w_{s}=(1-\beta) \cdot r U_{s}\left(\theta_{s}\right)+\beta \cdot\left(x_{\min } \cdot y_{s}-r V_{s}\left(\theta_{s}\right)\right)
$$

All other irregular entrepreneurs adopt $w_{s}$. This can be justified by their greater ability $(x)$, which can also be used in bargaining.

The higher productivity level in the regular sector allow workers who seek job in this sector (and who will also be the more educated (see subsection 3.1)) to bargain a higher wage, whatever the size of the regular sector, so that $w_{r}>w_{s}$, as it emerges from the literature (Rauch, 1991; Fugazza and Jacques, 2003; Kolm and Larsen, 2003; Amaral and Quintin, 2006; Boeri and Garibaldi, 2006; Albrecht et al., 2009). All other regular entrepreneurs adopt $w_{r}$, because they are also more able in bargaining. Therefore, the entrepreneurs appear to workers as homogeneous in each sector, and workers appear to the entrepreneurs as homogeneous (and able to properly invest in education (see subsection 3.1)), so that matching is random. The property that $w_{i}{ }^{\prime}\left(\theta_{i}\right)>0 \forall i$ holds, since $V_{i}{ }^{\prime}\left(\theta_{i}\right)<0$, and $U_{i}{ }^{\prime}\left(\theta_{i}\right)>0 \forall i$.

The surplus of a job in each sector is defined as the sum of the worker's and firm's value of being on the job, net of the respective outside options, so that $S_{i}=J_{i}-V_{i}+W_{i}-U_{i}$. Using the Bellman equations, we get:

$$
S_{s}=\frac{x_{s} \cdot y_{s}-z+c_{s}}{r+\delta+\rho+(1-\beta) \cdot f\left(\theta_{s}\right)+\beta \cdot g\left(\theta_{s}\right)} ; \quad S_{r}=\frac{x_{r} \cdot y_{r}-\tau-z+c_{r}}{r+\delta+(1-\beta) \cdot f\left(\theta_{r}\right)+\beta \cdot g\left(\theta_{r}\right)} .
$$

\footnotetext{
${ }^{6}$ We neglect possibilities of moonlighting, so that workers can perform only one activity at a time.
} 
Note that the surpluses are heterogeneous within the two sectors, besides being different between them. This is due to the overall heterogeneity of entrepreneurial ability. The expected present values of vacancies for firms can be also obtained, since $\left(J_{s}-V_{s}\right)=(1-\beta) \cdot S_{s}$ and $\left(J_{r}-V_{r}\right)=(1-\beta) \cdot S_{r}$, i.e.:

$$
\begin{aligned}
& r V_{s}=\frac{f\left(\theta_{s}\right) \cdot(1-\beta) \cdot\left(x_{s} \cdot y_{s}-z\right)-c_{s} \cdot\left(r+\delta+\rho+\beta \cdot g\left(\theta_{s}\right)\right)}{r+\delta+\rho+(1-\beta) \cdot f\left(\theta_{s}\right)+\beta \cdot g\left(\theta_{s}\right)} \\
& r V_{r}=\frac{f\left(\theta_{r}\right) \cdot(1-\beta) \cdot\left(x_{r} \cdot y_{r}-\tau-z\right)-c_{r} \cdot\left(r+\delta+\beta \cdot g\left(\theta_{r}\right)\right)}{r+\delta+(1-\beta) \cdot f\left(\theta_{r}\right)+\beta \cdot g\left(\theta_{r}\right)}
\end{aligned}
$$

As in Fonseca et al. (2001), we ignore the range beyond which $\theta_{i}$ is large enough to turn $r V_{i}$ negative. Hence, it must be that $\theta_{i} \in\left[0, \tilde{\theta}_{i}\right) \forall i$, where $\tilde{\theta}_{i}<\infty$ is the value such that $V_{i}\left(\tilde{\theta}_{i}\right)=0$. Furthermore, since for $\theta_{i}=0$ the vacancy would be always filled, the relevant interval for $\theta_{i}$ becomes $\theta_{i} \in\left(0, \tilde{\theta}_{i}\right) \forall i$, which implies $u \neq 0, v_{i} \neq 0 \forall i$.

\subsection{Entrepreneurial ability and the underground sector}

A key feature of the model is that the comparison between the expected profitability of posting vacancies in the two sectors depends on the entrepreneurial ability of individuals $(x)$. More precisely, let us assume the following.

Assumption 2. Entrepreneurial ability $x$ is distributed over a unitary set of a continuum of infinitely-living individuals who expect to participate in production activity either as entrepreneurs or as workers. This ability can be measured in continuous manner, $x \in\left[0, x_{\max }\right]$, following the known c.d.f. $F:\left[0, x_{\max }\right] \rightarrow[0,1]$.

The individual must be endowed with a minimum level of entrepreneurial ability in order to open a vacancy, thus becoming an entrepreneur. As will shortly be made clear, this minimum level is required to enter the underground sector only, because the level of ability required to enter the regular sector is even higher. The minimum ability required to become an entrepreneur, labelled with $x_{\min }$, can thus be obtained from the zero-profit condition in the underground sector, i.e. from $V_{s}-U_{s}=0$, because an individual with entrepreneurial ability $x$ can always choose between posting a vacancy and searching for a job:

$\lim _{v_{s} \rightarrow 0}\left[V_{s}=U_{s}\right] \Rightarrow x_{\text {min }}=\frac{2 z}{y_{s}}>0$ 
This result is due to the following: $\lim _{\theta_{s} \rightarrow 0} U_{s}=z$, which is straightforward from the Bellman equation for $U_{s}$, and $\lim _{\theta_{s} \rightarrow 0} V_{s}=x y_{s}-z$ by applying the l'Hôpital rule in equation [1].

Therefore, the zero-profit condition can be used to distinguish entrepreneurs from workers. ${ }^{7}$ Since for $r>0, w_{i} \geq z \forall i$, then $W_{i}-U_{i} \geq 0$. Indeed, from the free-entry condition, we get that the productivity level of the less able entrepreneur $\left(y_{s} \cdot x_{\min }\right)$ is twice the opportunity cost of employment $(z)$. Hence, the worker finds it always optimal to work for the current employer instead of searching for a new one.

Lemma 1. All the individuals endowed with $x \geq x_{\min }$ expect to profitably open a vacancy, thus becoming entrepreneurs, while the individuals, labelled with $l$ and endowed with $x<x_{\min }$, will not post any vacancy, thus becoming workers.

Note that entrepreneurs will earn extra-profit as a rent in posting vacancies, because ability is not tradeable.

Let us now define a threshold level of entrepreneurial ability $T \in\left[x_{\min }, x_{\max }\right]$ such that two entrepreneurs drawn from the two sectors yield equal expected profitability, i.e.:

$V_{r}(x=T)=V_{s}(x=T)$

$T$ can therefore be derived from equations [1], [2], and [3]:

$T=\frac{\left(\tau+z+c_{r} \cdot A\right)(B+1)-\left(z+c_{s} \cdot B\right)(A+1)}{y_{r}(B+1)-y_{s}(A+1)}$

with $A \equiv \frac{r+\delta+\beta \cdot g\left(\theta_{r}\right)}{(1-\beta) \cdot f\left(\theta_{r}\right)}$ and $B \equiv \frac{r+\delta+\rho+\beta \cdot g\left(\theta_{s}\right)}{(1-\beta) \cdot f\left(\theta_{s}\right)}$.

Equation [4] defines $T$ as a special $x$, so that the condition $x \geq x_{\min }>0$ requires that $T>0$. Sufficient conditions for $T>0$ are that both the numerator and the denominator of [4] are positive. The numerator is positive if $(\tau+z)>c_{s}, c_{r}>z$, and $c_{r}>c_{s}$, which are realistic conditions. ${ }^{8}$ The denominator is positive if $y_{r}$ is sufficiently greater than $y_{s}$, which is a necessary condition for the regular sector to be able to survive, and it qualifies our Assumption 1.

\footnotetext{
${ }^{7}$ In a framework in which the number of firms is fixed, the zero-profit condition is no longer used to determine the labour-market tightness (see Fonseca et al., 2001, and Pissarides, 2002).

${ }^{8}$ The value of the start-up cost in the underground sector $c_{s}$ should be very low, since ease of entry is often one of the criteria used to define the informal sector (Gërxhani, 2004). By contrast, the start-up cost $c_{r}$ is often very heavy because of regulations, administrative burdens, licence fees, bribery (Bouev, 2005).
} 
A further result can be obtained from these restrictions: the intercept of $V_{r}(x)$ is lower than the intercept of $V_{s}(x)$, and the slope of $V_{r}(x)$ is steeper than the slope of $V_{s}(x)$ (see Fig. $3)$.

$========$ Fig. 3 about here (now at the end) $==========$

From the macroeconomic point of view, the entrepreneurs' indifference condition [3] implies that, given the set of entrepreneurs $1-l$, the share of entrepreneurs who open a vacancy in the regular sector is:

$1-F(T)=v_{r}$

while the share

$F(T)-l=v_{s}$

opens a vacancy in the underground sector. Entrepreneurs may thus post a vacancy and then fill the job, or fail to fill it, in one of the two sectors, so that it can be simply stated that $v_{r}=1-\left(v_{s}+l\right) .{ }^{9}$ Hence, equation [4] can be re-written in a more general form as follows:

$T=T\left(v_{s}\right)$

Equation [7] makes evident the relationship between the two variables $v_{s}$ and $T$, and it can thus be called $T$-curve. Only the variable $v_{s}$ appears in [7] because in this subsection the variable $u$ appearing in [4] is taken as exogenous, thus underlining the fact that it is taken by entrepreneurs as given, while in the next subsection $u$ will be a function of $v_{s}$.

The relationship is negative in the equation [7] because of the wage cost effect, and the effect due to search or congestion externalities (see Pissarides, 2000). In fact, if the irregular vacancies increase, wages increase, and the probability of filling them is lower. Hence, it is more difficult to fill an irregular vacancy and fewer entrepreneurs enter the irregular sector. It can be proved that $\partial T / \partial v_{s}<0$ under restrictions very similar to those required for $T=T\left(v_{s}\right)>0($ see Appendix A).

Equation [7] can be coupled with equation [6], which represents the distribution of ability across (irregular) entrepreneurs. In this equation $v_{s}$ is monotonically rising in $T$ from $x_{\min }$ up to $x_{\max }$. Both equations [6] and [7] can thus be depicted in the diagram with axes $\left[v_{s}, T\right]$, as in Fig. 4. Equation [7] has been built under the following condition:

\footnotetext{
${ }^{9}$ In this model, the number of incumbent entrepreneurs, who run $n_{r}+n_{s}$ firms, is exogenous, and adds to those who enter the market. Matters thus become simpler without loss of generality.
} 
$\lim _{v_{s} \rightarrow 0} T=\frac{\left(\tau+z+c_{r} \cdot A\right)-z \cdot(A+1)}{y_{r}-y_{s}(A+1)} \geq x_{\min }$

so that the available entrepreneurial ability is sufficient to open some vacancies.

Lemma 2. A unique intersection between the two curves exists, thus determining the partial equilibrium of the model, since $u$ is taken as given.

$=========$ Fig. 4 about here (now at the end) $==========$

From this result, and from the previous one represented in Fig. 3, a further result follows, thus substantiating the statement that the minimum level of entrepreneurial ability to profitably open a new vacancy, i.e. $x_{\min }$, strictly regards the underground sector.

Lemma 3. The less able entrepreneurs open irregular vacancies; the abler entrepreneurs open regular vacancies.

\subsection{Unemployment and the steady state general equilibrium}

Although the economy has two sectors, we empirically observe a single rate of unemployment, which is defined thus:

$u=l-n_{r}-n_{s}$

where $n_{r}$ and $n_{s}$ represent steady-state employment in the regular and underground sector, respectively. Since jobs arrive to unemployed workers at the rate $g\left(\theta_{i}\right)$, with $i \in\{r, s\}$, and regular and irregular filled jobs are destroyed at the rate $\delta$ and $(\delta+\rho)$, respectively, then in the steady-state equilibrium it must be that:

$\delta \cdot n_{r}=u \cdot g\left(\theta_{r}\right)$

$(\delta+\rho) \cdot n_{s}=u \cdot g\left(\theta_{s}\right)$

Given the assumptions in the previous subsection, we can view $u \cdot g\left(\theta_{r}\right)$ and $u \cdot g\left(\theta_{s}\right)$ as the share of skilled and unskilled workers who find jobs, respectively. Steady-state unemployment is thus given by equations [8], [9] and [10]:

$u=\frac{l}{\frac{g\left(\theta_{r}\right)}{\delta}+\frac{g\left(\theta_{s}\right)}{\delta+\rho}+1}$

This equation can be rewritten in general and explicit form as follows:

$u=u\left(v_{s}\right)$

where steady-state unemployment $u$ is a function of vacancies in the underground sector only, since $\theta_{r}=\left(1-l-v_{s}\right) / u$ and $\theta_{s}=v_{s} / u$. Equation [12] can be depicted as a U-shaped curve in 
the $\left(v_{s}, u\right)$-axes over the range $\left.v_{s} \in\right] 0,(1-l)[$, with perfect symmetry in the case of $\rho=0$ (see Appendix A).

Equation [12] closes the general equilibrium model formed by the system including the three main equations [4], [6] and [12] in the three unknowns $v_{s}, T$, and $u$. It is intuitive that the equilibrium result obtained in the previous subsection (where $u$ was taken as given), which concerned with the intersection between the curves represented in [6] and [7], does not qualitatively change under the condition that $u$ changes through equation [12] only moderately. It can be proved that this condition is $-\frac{1}{\theta_{r}}<\frac{\partial u\left(v_{s}\right)}{\partial v_{s}}<\frac{1}{\theta_{s}}$, which obviously holds for intermediate levels of $v_{s}$ (see Appendix A).

It can also be proved that the equilibrium result does not qualitatively change even in the complementary conditions, i.e. $\frac{\partial u\left(v_{s}\right)}{\partial v_{s}}<-\frac{1}{\theta_{r}}$ and $\frac{\partial u\left(v_{s}\right)}{\partial v_{s}}>\frac{1}{\theta_{s}}$, which may hold when $v_{s}$ takes extreme values. In these two cases the macroeconomic condition of the labour market affects both the regular and the underground sector. In fact, for $v_{s}$ close to zero, $\partial u\left(v_{s}\right) / \partial v_{s}$ may be so negative that both $\theta_{s}$ and $\theta_{r}$ rise, but $\theta_{s}$ rises more than $\theta_{r}$, while for $v_{s}$ close to $(1-l), \partial u\left(v_{s}\right) / \partial v_{s}$ may be so positive that both $\theta_{s}$ and $\theta_{r}$ diminish, but $\theta_{s}$ diminishes less than $\theta_{r}$ (see Appendix A).

Therefore, this concluding proposition can be obtained.

Proposition 1. The solutions for the four key variables $v_{s}, v_{r}, T$ and $u$ are obtained by considering: 1) the present discounted values of the vacancies, i.e. equations [1] and [2]; 2) the entrepreneurs' indifference condition between open vacancies in the two sectors, given their entrepreneurial ability distribution, and the threshold level of entrepreneurial ability, i.e. equations [3] and [4]; 3) the unemployment identity [8] and the equilibrium condition of the transition flows on the supply side of the labour market, i.e. equations [9] and [10].

\subsection{Discussion}

The main result of the model of this section is that not only is there an interior solution whereby both the underground sector and the regular sector survive in equilibrium (Boeri and Garibaldi, 2006; Albrecht et. al., 2009), but this equilibrium is determined by allocating heterogeneous entrepreneurial ability between the two sectors (Rauch, 1991; Carillo and Pugno, 2004). This may explain the so-called "shadow puzzle", i.e. the persistence of the underground sector despite advances in detection technologies and greater organisation by 
public authorities to reduce irregularities (issue ( $i)$ in the Introduction). This kind of explanation runs counter to the argument that the underground sector is an incubator of infant industries (see also La Porta and Shleifer, 2008; Rauch, 1991; Levenson and Maloney, 1998).

A number of other important results can be drawn from comparative statics exercises, although described in dynamic terms for shortness. A general exercise concerns the effects of the shift of the $T$-curve due to changes in some parameters. Its downward shift decreases both the (partial) equilibrium of $v_{s}$ in Fig. 4, and the model's (general) equilibrium of $v_{s}$, and hence also $\theta_{s}$. Therefore, this downward shift squeezes the proportion of the underground sector and expands the proportion of the regular sector, as clearly emerges from equations [5] and [6], and as can be easily derived from equations [8], [9] and [10] jointly.

The downward shift of the $T$-curve can thus increase overall output, because it increases the proportion of the most productive sector. The regular sector is in fact more productive than the underground sector for two reasons: the regular sector exhibits a greater labour productivity, and the most able entrepreneurs prefer this sector. In fact, for a greater number of regular vacancies made possible by the shift of the abler entrepreneurs from the underground sector, both the number of regular matches, $m_{r}=m\left(v_{r}, u\right)$, and skilled employment, $n_{r}$, are greater because of the greater probability to find a regular job.

The main policy implications can be drawn from the effects of the changes in the policy parameters on $T$, and hence on the proportion of the underground sector, i.e.: $\frac{\partial T}{\partial \rho}<0 ; \frac{\partial T}{\partial \tau}>0 ; \frac{\partial T}{\partial c_{r}}>0$.

In words, closer monitoring, lower taxation and lower start-up costs reduce the underground sector. This is in line with the conclusions of other models (see e.g. Friedman et al., 2000; Johnson et al., 2000; Sarte, 2000; Bouev, 2005).

A new contribution of this model regards a much more controversial question, i.e. the ambiguous relationship between the underground economy and unemployment (issue (ii) in the Introduction). This relationship is represented by the equation [12], which is U-shaped, thus showing that $\partial u\left(v_{s}\right) / \partial v_{s}<0$ when $v_{s}$ is relatively small, and $\partial u\left(v_{s}\right) / \partial v_{s}>0$ when $v_{s}$ is relatively great. But if $\rho$ increases, then the minimum of $u=u\left(v_{s}\right)$ shifts in the region where $v_{s}$ is closer to zero. A more precise Proposition can thus be stated:

Proposition 2. If $v_{s} \leq v_{r}$, the relationship between $v_{s}$ and $u$ is negative if $\rho$ is sufficiently low, it is positive if $\rho$ is sufficiently high. If $v_{s}>v_{r}$ the relationship between $v_{s}$ and $u$ is positive for any $\rho$ (see Appendix $B$ for proof). 
This is an interesting result from the policy implications point of view. In fact, the role of the monitoring parameter is strengthened, since any policy intended to reduce the irregular sector may also reduce the unemployment rate if $\rho$ is sufficiently high. ${ }^{10}$

\section{THE MODEL WITH INVESTMENT IN EDUCATION AND ENDOGENOUS PRODUCTIVITY}

\section{GROWTH}

\subsection{A steady-growth solution of the model}

This paper assumes that human capital accumulation is the primary engine of economic growth. In the growth literature, workers' human capital usually refers to "the average level of educational attainment" (Nelson and Phelps, 1966; Benhabib and Spiegel, 1994) or similarly to "the average total years of schooling" (Savvides and Stengos, 2009). ${ }^{11}$ Specifically, education and schooling enable workers to absorb knowledge and acquire additional human capital once employed (Rosen, 1976; Stokey, 1991; Laing et al., 1995). Therefore, it can be stated that the higher the level of schooling or knowledge $(k)$ and the larger the human capital accumulation $(h)$, the higher is the rate of economic growth.

To simplify matters, and without loss of generality, we assume $h=k$, so that education and human capital will be used interchangeably. Then, let us specify a simple equation for the rate of productivity growth $(\gamma)$ :

$$
\gamma=\gamma(h) \quad \text { with } \gamma^{\prime}(h)>0, \gamma^{\prime \prime}(h)<0
$$

with the further property that $r>\gamma(h) \forall h$, in order to keep present values finite.

Since the education level and skill in the workers employed in the regular sector are higher than those in the underground sector (Albrecht et. al., 2009; Cappariello and Zizza, 2009), growth is expected to be faster in the regular sector. This link is assumed in the form of labour-augmenting technological progress à la Pissarides (2000), ${ }^{12}$ where, specifically, workers' human capital plays two roles, as suggested by Laing et al. (1995). In fact, since human capital is firstly acquired through formal education, workers can be employed with an initial productivity $\left(y_{0}\right)$ that depends on the level of schooling $(h)$. Secondly, workers' productivity increases according to equation [12]. Let us then state the following assumption.

\footnotetext{
${ }^{10}$ Bosch and Esteban-Pretel (2009) focus on the role of the job destruction rate. According to their matching model, policies that reduce the cost of formality (or those that increase the cost of informality) produce an increase in the share of formal employment while also reducing unemployment because the reallocation between formal and informal jobs has non-neutral effects on the unemployment rate, since informal jobs record much higher separation rates.

${ }^{11}$ Indeed, the latter is often used as a quantitative proxy in empirical estimations (Savvides and Stengos, 2009).

${ }^{12}$ In our terms, Pissarides's (2000) simple specification is: $y_{r}(h, t)=y_{0} \cdot e^{\gamma(h) \cdot t}$.
} 
Assumption 3. The total discounted value of productivity in the regular sector is given by:

$y_{r}(h)=\int_{0}^{\infty} e^{-r \cdot t} \cdot y_{0}(h) \cdot e^{\gamma(h) \cdot t} d t \Rightarrow \frac{y_{0}(h)}{r-\gamma(h)}$

where:

$y_{0}=y_{0}(h) \quad$ with $y_{0}{ }^{\prime}(h)>0, \lim _{h \rightarrow 0} y_{0}>0, \lim _{h \rightarrow \infty} y_{0}<\infty$

Productivity in the underground sector is given by:

$y_{s}=\varphi \cdot y_{r}(h) \quad$ with $0<\varphi<1$

According to this assumption, the underground sector partially benefits from this process because of spill-over effects in the diffusion of knowledge. Therefore, both sectors can grow at the same rate $\gamma(h)$, while the level of productivity in the regular sector remains higher than that of productivity in the underground sector.

In order to endogenise the rate of productivity growth, let us consider the optimal choice of education for individuals, given that schooling investment is costly (cf. Laing et al., 1995; Decreuse and Granier, 2007), and that only regular firms profitably employ educated workers. Formally:

Assumption 4. Let the cost function of education be $c(k)$, with $c^{\prime}(k)>0, c^{\prime \prime}(k)>0$ and $\partial c(0) / \partial k=0$, because of either a direct pecuniary cost or the disutility from scholastic effort. Each job-seeker in the regular sector solves the following program, before entering the labour market: ${ }^{13}$

$\max _{k \geq 0}\left\{\left[w_{r}\left(y_{r}(k)\right)-w_{s}\right]-c(k)\right\}$

where $w_{r}\left(y_{r}(k)\right)-w_{s}$ is the net gain from investing in education, i.e. the wage differential. The optimal investment in education can be thus obtained by the usual condition:

$\Rightarrow \frac{\partial w_{r}\left(y_{r}(k)\right)}{\partial k}=\frac{\partial c(k)}{\partial k}$

Condition [16] shows a positive relationship between $\theta_{r}$ and $k$, i.e. $\frac{\partial k}{\partial \theta_{r}}>0$, besides the implication that $k^{*}>0$, since $\frac{\partial w_{r}}{\partial \theta_{r}}>0$. In fact, a rise in $\theta_{r}$ increases the regular wages. Hence, in order to search for a job (work) in the regular sector, more workers choose to invest

\footnotetext{
${ }^{13}$ Workers invest in education when young, and having completed their schooling, they search for employment (Laing et al., 1995). Unlike Laing et al. (1995) and Decreuse and Granier (2007), in this model the optimal choice of education is linked to the wage differential rather than to the value of searching for a job.
} 
in education. In turn, the higher the optimal investment in education, the greater is human capital and the greater is the productivity level of the economy. Therefore, the increase in the size of the regular sector, i.e. $\theta_{r}$, spurs economic growth by a higher investment in education.

It follows that, from a macroeconomic point of view, the investment in education is on the one hand negatively linked to the size of the underground sector, and on the other, positively linked to productivity growth of the economy through Assumption 3 and the equation $h=k$. The following Proposition can thus be stated.

Proposition 3. The solution of the steady-state model can be extended to include the optimal investment in education $\left(k^{*}\right)$, and the rate of productivity growth of the economy $(\gamma)$, thus finding a steady-growth solution.

These results, together with Proposition 2 of the previous section regarding the relationship between the underground economy and unemployment, help understand the relationship between economic growth and unemployment (issue (iii) in the Introduction). Indeed, the relationship between $\gamma(h)$ and $u$ is positive if $\rho$ is low, this relationship is negative if $\rho$ is high, under the condition that $v_{s} \leq v_{r}$.

Our analysis is thus able to reconcile the conflicting results found in the literature on growth and unemployment. This suggestion is alternative to Aghion and Howitt's approach, nevertheless it refers to the structure of the economy. Since the condition $v_{s} \leq v_{r}$ is the usual condition throughout the world, the monitoring rate becomes a very important parameter. Not only does it affect the size of the underground sector, but it may positively affect both unemployment and economic growth.

\subsection{The case of multiple equilibria}

The extended model may also be adapted in order to account for a relevant case: that of regional dualism, i.e. the failure of the more backward region to catch up with the more developed region.

Let us assume that $y_{0}(h)$ is a logistic function, i.e. it performs increasing returns to human capital before the usual and eventual decreasing returns. This form may be due to thresholds in human capital, i.e. once human capital attains a certain threshold level (critical 
mass) productivity may reach a higher steady-state level (Azariadis and Drazen, 1990). This pattern has also received some empirical evidence (Savvides and Stengos, 2009). ${ }^{14}$

Under this assumption, the relationship between $T$ and $v_{s}$ may change significantly. Indeed, if the functions [13] and [15] are plugged into [4], then multiple equilibria become possible since the $T$-curve may display an increasing part in the middle, thus cutting the other curve twice, as depicted in Fig. 4 (dotted line). ${ }^{15}$

The two extreme equilibria may be labelled as "good" and "bad" because they define two different conditions where the proportion of the underground sector is small and, respectively, large, with the consequent desirable and undesirable characterisations. Specifically, in the "good" equilibrium one region exhibits higher productivity, a more efficient use of entrepreneurial ability, higher investment in education, greater employment of skilled workers, and, finally, a higher rate of economic growth with respect to the region in the "bad" equilibrium.

This result is interesting because it can represent an economy characterised by a uniform institutional set-up, as captured by the same parameters of the model, but with two regions that differ in their histories, as captured by the initial economic structure. The region that has inherited a greater proportion of the underground sector may converge towards the "bad" equilibrium. The region that has inherited a smaller proportion of the underground sector may converge towards the "good" equilibrium. However, the region in the "bad" equilibrium does not catch up with the other region, because it exhibits a lower steadygrowth. This case seems to be the best fit with the Italian North-South divide, which is special but not unique in the world. This case is also interesting theoretically, because it shows the crucial importance of the allocation of entrepreneurship for economic development.

\section{CONCLUSIONS}

Several empirical studies clearly document that the underground sector persists with a different size in many and various countries around the world, thus raising the 'shadow puzzle'. Related studies also show that a less clear pattern emerges in the relationship between the size of the underground sector and unemployment. Another unclear pattern has

\footnotetext{
${ }^{14}$ The models which describe general nonlinearities in the relationship between growth and human capital do not provide specific functional forms (Savvides and Stengos, 2009). Azariadis and Drazen (1990) even study a step functional form, where thresholds are more than one.

${ }^{15}$ As shown by Savvides and Stengos (2009) - adapted from Azariadis and Drazen (1990) - a step functional form may generate the possibility of multiple equilibria, with different balanced growth paths. This growth process comes to an end when "labour productivity attains the highest possible value and the system settles down on the ultimate stage of growth" (Azariadis and Drazen, 1990, p. 517).
} 
been observed in the literature on economic growth, i.e. the pattern regarding the relationship between growth and unemployment. However, microeconomic studies have found that underground firms employ relatively backward technology, less skilled and less educated workers, as well as less able entrepreneurs, i.e. lower quality inputs for growth. This microeconomic evidence has suggested useful links to build up a matching type of model that is able to account for both the 'shadow puzzle', and the two evidenced unclear patterns.

The assumption that entrepreneurial ability is a heterogeneous input for production is rather new in matching models. However, it can increase their explanatory power, because heterogeneous entrepreneurs can well-match to workers with different skills, thus forming firms with rather different productivity. In this way, less productive firms can persistently survive by evading taxes, and can discourage human capital accumulation and hence productivity growth.

Monitoring firms' regularity appears to be the key parameter for determining whether or not unemployment is complementary with underground employment, and, consequently, whether unemployment is positively or negatively correlated with economic growth. As shown in Figures 1 and 2, low levels of monitoring appear to make unemployment positively correlated with economic growth, and high levels of monitoring appear to make unemployment negatively correlated with economic growth.

The paper has also been able to account for the special case of regional dualism, as in the Italian case, where the more backward South diverges from the North, although both regions share the same institutional set-up. This case may arise if non-linearities in the human capital accumulation function produce multiple equilibria in the size of the underground sector.

Finally, a number of policy implications follow from this analysis. Reducing the tax burden becomes especially effective if monitoring is at a high level, because underground firms are discouraged without raising unemployment. In the long run, this may also enhance growth. These same results follow if monitoring is itself increased. In the case of regional dualism, a one-shot change in the policy parameters may trigger an endogenous dynamic of convergence between the two regions. More generally, an effective policy should seek to increase entrepreneurial ability, typically through education, so that overall economic performance improves, both because of the sectoral composition effect, and because of the positive level effect of each firm. 


\section{APPENDICES}

\section{Appendix A: Proof that $\partial T / \partial v_{s}<0$}

It will be firstly proved that $\partial T / \partial v_{s}<0$ (with $0<v_{s}<(1-l)$ and $v_{r}=1-l-v_{s}$ ) when $u$ is assumed as exogenous, as in subsection 2.2, and then when $u$ is assumed as endogenous, as in subsection 2.3.

Sufficient conditions for $\partial T / \partial v_{s}<0$ are that $\partial N / \partial v_{s}<0$ and $\partial D / \partial v_{s}>0$, where $N$ and $D$ are the numerator and the denominator of $T$ in [4], both divided by $(A+1)(B+1)$. To prove this, let us observe, from the definitions of $A$ and $B$ in [4], that $\partial A / \partial v_{s}<0$ and $\partial B / \partial v_{s}>0$, because $\partial A / \partial \theta_{r}>0, \partial \theta_{r} / \partial v_{s}<0$, and $\partial B / \partial \theta_{s}>0, \partial \theta_{s} / \partial v_{s}>0$. Therefore, $\partial N / \partial v_{s}$ is negative if $c_{r}>(\tau+z)$ and $c_{s}>z$, as it emerges from the derivative of $N$ :

$\frac{\partial}{\partial v_{s}}\left(\frac{\tau+z+c_{r} A}{A+1}-\frac{z+c_{s} B}{B+1}\right)=\frac{\partial A}{\partial v_{s}}\left(\frac{c_{r}(A+1)-\left(\tau+z+c_{r} A\right)}{(A+1)^{2}}\right)-\frac{\partial B}{\partial v_{s}}\left(\frac{c_{s}(B+1)-\left(z+c_{s} B\right)}{(B+1)^{2}}\right)$

while $\partial D / \partial v_{s}$ is always positive, as it emerges from the derivative of $D$ :

$\frac{\partial}{\partial v_{s}}\left(\frac{y_{r}}{A+1}-\frac{y_{s}}{B+1}\right)=\frac{\partial B}{\partial v_{s}} \frac{y_{s}}{(B+1)^{2}}-\frac{\partial A}{\partial v_{s}} \frac{y_{r}}{(A+1)^{2}}$

The restriction set of the parameters for both $T>0$ and $\partial T / \partial v_{s}<0$ thus becomes: $c_{r}>(\tau+z)>c_{s}>z$, and $y_{r}$ sufficiently greater than $y_{s}$.

Subsection 2.3 assumes that $u$ is endogenous through equation [12]. This equation is $\mathrm{U}$-shaped within the relevant range of $v_{s}$. In fact, the derivative of $u\left(v_{s}\right)$ can thus be calculated through some manipulations (more mathematical details are available on request from the authors):

$$
\frac{\partial u}{\partial v}=\frac{\frac{g^{\prime}\left(\theta_{r}\right)}{\delta}-\frac{g^{\prime}\left(\theta_{s}\right)}{\delta+\rho}}{\frac{g\left(\theta_{s}\right)}{\delta+\rho}-\frac{\theta_{s} g^{\prime}\left(\theta_{s}\right)}{\delta+\rho}+\frac{g\left(\theta_{r}\right)}{\delta}-\frac{\theta_{r} g^{\prime}\left(\theta_{r}\right)}{\delta}+1}
$$

While the denominator of [A.3] is always positive because $g\left(\theta_{i}\right)$ is a concave function so that $g\left(\theta_{i}\right) / \theta_{i}>g\left(\theta_{i}\right)$, the numerator is negative for relatively small $v_{s}$, and it is positive for relatively great $v_{s}$, because, again, $g\left(\theta_{i}\right)$ is a concave function. 
The fact that $u\left(v_{s}\right)$ is U-shaped maintains that $\partial N / \partial v_{s}<0$ and $\partial D / \partial v_{s}>0$, so that $\partial T / \partial v_{s}<0$. This can be proved by distinguishing the intermediate range of $v_{s}$ around the minimum of $u\left(v_{s}\right)$, from the extreme ranges, where $v_{s}$ is either close to zero or close to $(1-l)$. In the former case, $\partial u\left(v_{s}\right) / \partial v_{s}$ is relatively small, so that it can satisfy these conditions: $-\frac{1}{\theta_{r}}<\frac{\partial u\left(v_{s}\right)}{\partial v_{s}}<\frac{1}{\theta_{s}}$, which guarantee that $\partial \theta_{r} / \partial v_{s}<0$ and $\partial \theta_{s} / \partial v_{s}>0$, and thus also that $\partial A / \partial v_{s}<0$ and $\partial B / \partial v_{s}>0$, because $\frac{\partial\left(\left(1-l-v_{s}\right) / u\left(v_{s}\right)\right)}{\partial v_{s}}=-\frac{1}{u}\left(\frac{1}{u} \frac{\partial u\left(v_{s}\right)}{\partial v_{s}}+\left(1-l-v_{s}\right)+1\right)$ and $\frac{\partial\left(v_{s} / u\left(v_{s}\right)\right)}{\partial v_{s}}=\frac{1}{u}\left(1-\theta_{s} \frac{\partial u\left(v_{s}\right)}{\partial v_{s}}\right)$. This case also holds for the extreme ranges of $v_{s}$, if $g\left(\theta_{i}\right)$ is not very concave.

In the lower range of $v_{s}$, where it is close to zero, the condition $-\frac{1}{\theta_{r}}>\frac{\partial u\left(v_{s}\right)}{\partial v_{s}}$ emerges, if $g\left(\theta_{i}\right)$ is very concave, as in the Cobb-Douglas specification of the matching equation. In this case, the derivatives $\partial \theta_{r} / \partial v_{s}$ and $\partial A / \partial v_{s}$ take the "perverse" positive sign, while $\partial \theta_{s} / \partial v_{s}$ and $\partial B / \partial v_{s}$ maintain the positive sign, although increasing in size both because the numerator of $\theta_{s}$ rises, and because its denominator diminishes. The limit of [A.1] makes it evident that $\partial N / \partial v_{s}<0$ :

$\lim _{v_{s} \rightarrow 0} N=\frac{\partial A}{\partial v_{s}}\left(\frac{c_{r}-t-z}{(A+1)^{2}}\right)-\frac{\partial B}{\partial v_{s}}\left(c_{s}-z\right)$, which would be equal to $-\infty$ if the matching function were Cobb-Douglas. Similar reasoning can be applied to $D$, which would be equal to $\infty$ at the limit of the Cobb-Douglas case.

In the upper range of $v_{s}$, where it is close to $(1-l)$, the condition $\frac{\partial u\left(v_{s}\right)}{\partial v_{s}}>\frac{1}{\theta_{s}}$ emerges, if $g\left(\theta_{i}\right)$ is very concave. In this case, the derivatives $\partial \theta_{s} / \partial v_{s}$ and $\partial B / \partial v_{s}$ take the "perverse" negative sign, while the derivatives $\partial \theta_{r} / \partial v_{s}$ and $\partial A / \partial v_{s}$ maintain the negative sign, although becoming even more negative, both because the numerator of $\theta_{s}$ diminishes, and because its denominator rises. The limit of [A.1] makes it evident that, again, $\partial N / \partial v_{s}<0$ :

$\lim _{v_{s} \rightarrow 1-l} N=\frac{\partial A}{\partial v_{s}}\left(c_{r}-t-z\right)-\frac{\partial B}{\partial v_{s}} \frac{c_{s}-z}{(B+1)^{2}}$, which would be equal to $-\infty$ if the matching function were Cobb-Douglas. Similar reasoning can be applied again to $D$, which would be equal to $\infty$ at the limit of the Cobb-Douglas case. 


\section{Appendix B: Proof of Proposition 2}

Equation [12] is perfectly symmetric with respect to $v_{s}$ if $\rho=0$, so that $u\left(v_{s}\right)$ is at the minimum when $v_{s}=v_{r}$. If $\rho>0$, the minimum lies in the region where $v_{s}<v_{r}$. In fact, the condition for the minimum $\partial u\left(v_{s}\right) / \partial v_{s}=0$ that can be derived from [A.1] is $\frac{\delta+\rho}{\delta}=\frac{g^{\prime}\left(\theta_{s}\right)}{g^{\prime}\left(\theta_{r}\right)}$. This condition states that the greater is $\rho$, the smaller is the level of $v_{s}$ for which $u\left(v_{s}\right)$ is at the minimum. Therefore, for any given $v_{s}$ such that $\partial u\left(v_{s}\right) / \partial v_{s}<0$ at some level of $\rho$, there exists a sufficiently greater level of $\rho$ such that $\partial u\left(v_{s}\right) / \partial v_{s}>0$. Note that this result holds even if two different concave matching functions governed the two sectors, although the downward bound of the range of $v_{s}$ where $\partial u\left(v_{s}\right) / \partial v_{s}>0$ for any $\rho$ would be different from $v_{s}=v_{r}$.

Let us give a numerical example by using the Cobb-Douglas matching function, the parameters as given in the literature, such as the exponent of the function is equal to 0.5 , $\delta=0.15$, and let us assume that $l=0.5$, and that $v_{s}=0.15$, which is the $30 \%$ of the vacancies open in the whole economy. It thus emerges that $\partial u\left(v_{s}\right) / \partial v_{s}<0$ if $\rho=0.04$, and $\partial u\left(v_{s}\right) / \partial v_{s}>0$ if $\rho=0.08$. Both values for $\rho$ are close to those given by the literature (Boeri and Garibaldi, 2006; Busato and Chiarini, 2004).

\section{REFERENCES}

Agenor, Pierre-Richard, and Joshua Aizenman, (1999), "Macroeconomic adjustment with segmented labor markets," Journal of Development Economics, 58(2), 277-296, April.

Aghion, Philippe, and Peter Howitt, (1998), "Endogenous Growth Theory," Cambridge, MA, MIT Press.

Aghion, Philippe, and Peter Howitt, (1994), "Growth and Unemployment," Review of Economic Studies, 61(3), 477-94, July.

Albrecht, James, Lucas Navarro, and Susan Vroman, (2009), “The Effects of Labour Market Policies in an Economy with an Informal Sector," Economic Journal, 119(539), July, 1105-1129.

Amaral, Pedro S., and Erwan Quintin, (2006). "A Competitive Model of the Informal Sector." Journal of Monetary Economics, 53(7), 1541-53. 
Azariadis, Costas, and Allan Drazen, (1990), "Threshold Externalities in Economic Development," The Quarterly Journal of Economics, 105(2), 501-26, May.

Baumol, William J, (1990), "Entrepreneurship: Productive, Unproductive, and Destructive," Journal of Political Economy, 98(5), 893-921, October.

Banerjee, Abhijit V., and Esther Duflo, (2005), "Growth Theory through the Lens of Development Economics." In Handbook of Economic Growth, 1A, edited by Steve Durlauf and Philippe Aghion, 473-552. Holland: Elsevier Science.

Bean, Charles, and Christopher A. Pissarides, (1993), "Unemployment, consumption and growth," European Economic Review, 37(4), 837-854, May.

Benhabib, Jess, and Mark M. Spiegel, (1994), "The role of human capital in economic development evidence from aggregate cross-country data," Journal of Monetary Economics, 34(2), 143-173, October.

Boeri, Tito, and Pietro Garibaldi, (2002), "Shadow Activity and Unemployment in a Depressed Labour Market," CEPR Discussion Papers, 3433, June.

Boeri, Tito, and Pietro Garibaldi, (2006), "Shadow Sorting," Fondazione Collegio Carlo Alberto Working Paper Series, 10, May.

Bosch, Mariano, and Julen Esteban-Pretel, (2009), "Cyclical Informality and Unemployment," CIRJE F-Series Discussion Papers, 613, February.

Bouev, Maxim (2002), "Official Regulations and the Shadow Economy: A Labour Market Approach," William Davidson Institute Working Papers Series, 524, December.

Bouev, Maxim (2005), "State Regulations, Job Search and Wage Bargaining," William Davidson Institute Working Papers Series, 764, April.

Busato, Francesco and Bruno Chiarini (2004). "Market and underground activities in a twosector dynamic equilibrium model", Economic Theory, 23(4), 831-861.

Caballero, Ricardo J., (1993), "Comment on the Bean and Pissarides paper," European Economic Review, 37, 855-859;

Cappariello, Rita, and Roberta Zizza, (2009), "Dropping the books and working off the books," Temi di discussione (Economic working papers), 702, Bank of Italy, Gennaio.

Carillo, Maria Rosaria, and Maurizio Pugno, (2004), "The underground economy and underdevelopment," Economic Systems, 28(3), September, 257-279.

Cimoli, Mario, Annalisa Primi, and Maurizio Pugno, (2006), “A Low-Growth Model: Informality as a Structural Constraint," Cepal Review, 88, 85-102, April.

de Soto, Hernando, (1989), "The Other Path: The Invisible Revolution in the Third Worlds", New York: Harper and Row Publishers. 
Decreuse, Bruno, and Pierre Granier, (2007), "Matching frictions and the divide of schooling investment between general and specific skills," MPRA Paper, 6948.

Farrell, Diana, (2004), “The Hidden Dangers of the Informal Economy," McKinsey Quarterly, $3,26-37$.

Fonseca, Raquel, Lopez-Garcia Paloma, and Christopher A. Pissarides, (2001), "Entrepreneurship, start-up costs and employment," European Economic Review, 45(46), May, 692-705.

Friedman, Eric, Simon Johnson, Daniel Kaufmann, and Pablo Zoido-Lobaton, (2000), "Dodging the grabbing hand: the determinants of unofficial activity in 69 countries," Journal of Public Economics, 76(3), June, 459-493.

Friedman, Milton, (1968), "The Role of Monetary Policy," American Economic Review, 58(1), 1-17, March;

Fugazza, Marco, and Jean-Francois Jacques, (2003), "Labor market institutions, taxation and the underground economy," Journal of Public Economics, 88(1-2), January, 395-418.

Gërxhani, Klarita, (2004), "The Informal Sector in Developed and Less Developed Countries: A Literature Survey," Public Choice, 120(3-4), 09, 267-300.

Hoon, Hian Teck, and Edmund Phelps, (1997), "Growth, wealth and the natural rate: Is Europe's jobs crisis a growth crisis ?," European Economic Review, 41(3-5), 549-557.

Johnson, Simon, Daniel Kaufmann, John McMillan, and Christopher Woodruff, (2000), "Why do firms hide ? Bribes and unofficial activity after communism," Journal of Public Economics, 76(3), June, 495-520.

Kolm, Ann-Sofie, and Birthe Larsen, (2003), "Wages, Unemployment, and the Underground Economy," CESifo Working Paper, 1086, November.

Kolm, Ann-Sofie, and Birthe Larsen, (2010), "The Black Economy and Education," Research Papers in Economics, 2010:3.

Laing, Derek, Theodore Palivos, and Ping Wang, (1995), "Learning, Matching and Growth," Review of Economic Studies, 62(1), 115-29, January.

La Porta, Rafael, and Andrei Shleifer, (2008), "The Unofficial Economy and Economic Development," NBER Working Paper, 14520, December.

Levenson, Alec R., and William F. Maloney, (1998), "The informal sector, firm dynamics, and institutional participation," Policy Research Working Paper Series, 1988, September.

Lisi, Gaetano and Maurizio Pugno, (2010), "Entrepreneurship and the Hidden Economy: An Extended Matching Model," International Economic Journal, 24(4), 585-602. 
Lucas, Robert E., (1978), “On the Size Distribution of Business Firms," Bell Journal of Economics, 9(2), 508-523.

Lucas, Robert E., (1988), "On the Mechanics of Economic Development," Journal of Monetary Economics, 22(1), 3-42, July.

Mortensen, Dale T., and Christopher A. Pissarides, (1994), "Job Creation and Job Destruction in the Theory of Unemployment," Review of Economic Studies, 61(3), July, 397-415.

Mortensen, Dale T., and Christopher A. Pissarides, (1998), “Technological Progress, Job Creation and Job Destruction," Review of Economic Dynamics, 1(4), 733-753, October.

Mortensen, Dale T., (2005), “Alfred Marshall Lecture: Growth, Unemployment, and Labor Market Policy," Journal of the European Economic Association, 3(2-3), 236-258, $04 / 05$.

Muscatelli, Anton V., and Patrizio Tirelli, (2001), "Unemployment and Growth: Some Empirical Evidence from Structural Time Series Models," Applied Economics, 33(8), 1083-88, June.

Nelson, Richard R., and Edmond S. Phelps, (1966), "Investment in humans, technological diffusion, and economic growth," American Economic Review: Papers and Proceedings $51(2), 69-75$.

Petrongolo, Barbara, and Christopher A. Pissarides, (2001), "Looking into the Black Box: A Survey of the Matching Function," Journal of Economic Literature, 39(2), 390-431.

Phelps, Edmund S., (1968), "Money-Wage Dynamics and Labor-Market Equilibrium," Journal of Political Economy, 76, 678-711.

Pissarides, Christopher A., (2000), Equilibrium Unemployment Theory, The MIT Press (first edition 1990).

Pissarides, Christopher A., and Giovanna Vallanti, (2004), "Productivity Growth and Employment: Theory and Panel Estimates," CEP Discussion Papers dp0663, Centre for Economic Performance, LSE.

Pissarides, Christopher A., and Giovanna Vallanti, (2007). “The Impact Of Tfp Growth On Steady-State Unemployment," International Economic Review, 48(2), 607-640, 05.

Rauch, James E., (1991), "Modelling the informal sector formally," Journal of Development Economics, 35(1), January, 33-47.

Rebelo, Sergio, (1991), “Long-Run Policy Analysis and Long-Run Growth," Journal of Political Economy, 99(3), 500-521, June.

Romer, Paul M., (1986), "Increasing Returns and Long-run Growth,” Journal of Political Economy, 94(5), 1002-1037, October. 
Romer, Paul M., (1988), "Capital Accumulation in the Theory of Long-Run Growth," RCER Working Papers, 123.

Romer, Paul M., (1989), "Human Capital And Growth: Theory and Evidence," NBER Working Papers, 3173.

Rosen, Sherwin, (1976), “A Theory of Life Earnings," Journal of Political Economy, 84(4), S45-S67, (supplement), August.

Sarte, Pierre-Daniel G., (2000), "Informality and Rent-seeking Bureaucracies in a Model of Long-run Growth," Journal of Monetary Economics, 46(1), August, 173-197.

Savvides, Andreas, and Thanasis Stengos, (2009), "Human Capital and Economic Growth," Stanford University Press, Calif. : Stanford Economics and Finance.

Solow, Robert M., (1956), "A Contribution to the Theory of Economic Growth," The Quarterly Journal of Economics, 70 (1), 65-94, February.

Solow, Robert M., (1988), “Growth Theory: An Exposition,” (Radcliffe Lectures), Oxford: Oxford University Press.

Stokey, Nancy L., (1991), "Human Capital, Product Quality, and Growth," The Quarterly Journal of Economics, 106(2), 587-616, May.

Tripier, Fabien, (2006), "Sticky prices, fair wages, and the co-movements of unemployment and labor productivity growth," Journal of Economic Dynamics and Control, 30(12), 2749-2774, December.

Van Praag, Miriam C., and Salomon J. Cramer (2001), “The Roots of Entrepreneurship and Labour Demand," Economica, 68(269), 45-62. 


\section{FiguRES AND TABLES}

FIGURE 1. Unemployment vs Growth in EU countries (see Table 2 for the data details)

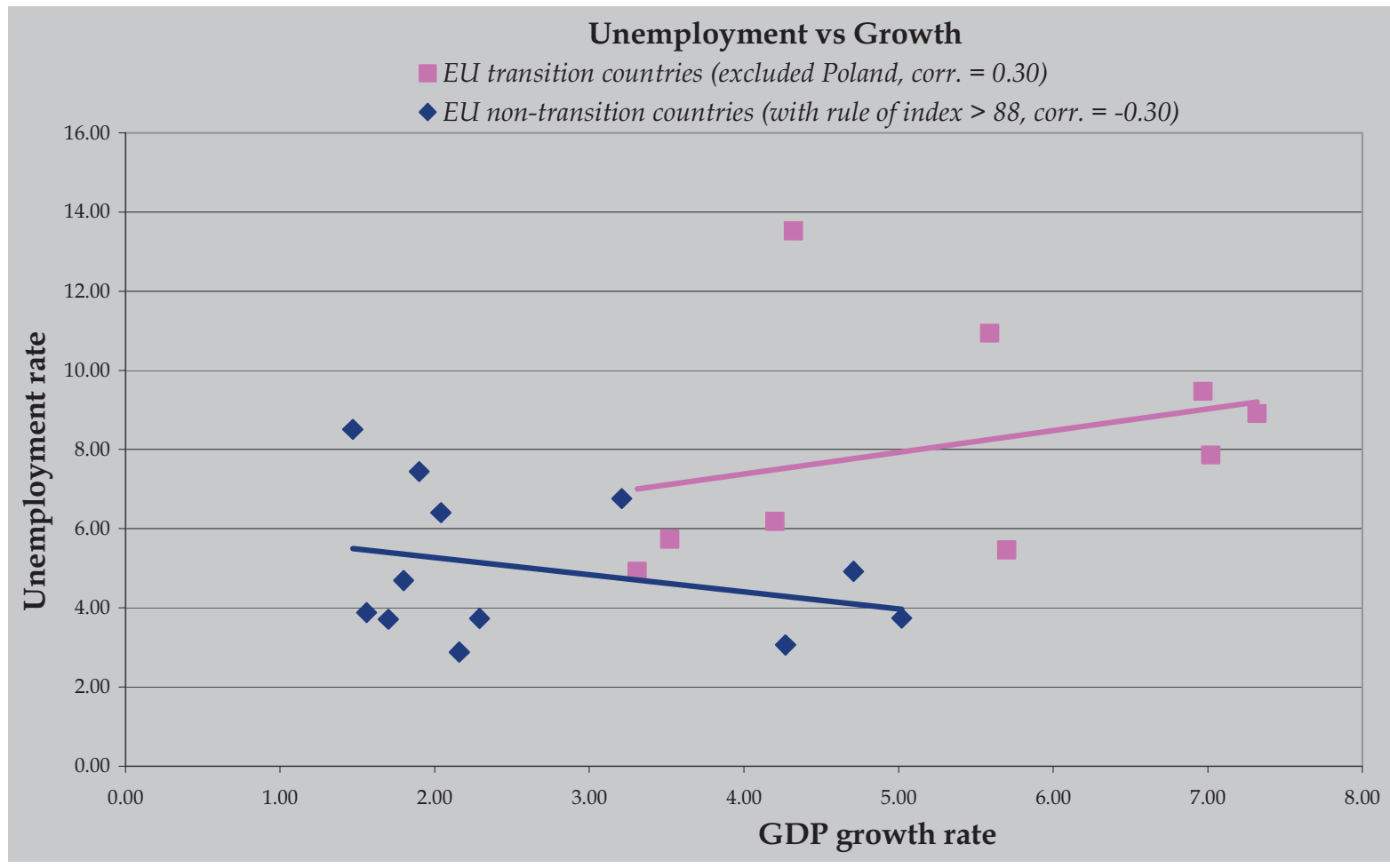

FIGURE 2. Unemployment vs Growth in Latin American countries (see Table 3 for the data details)

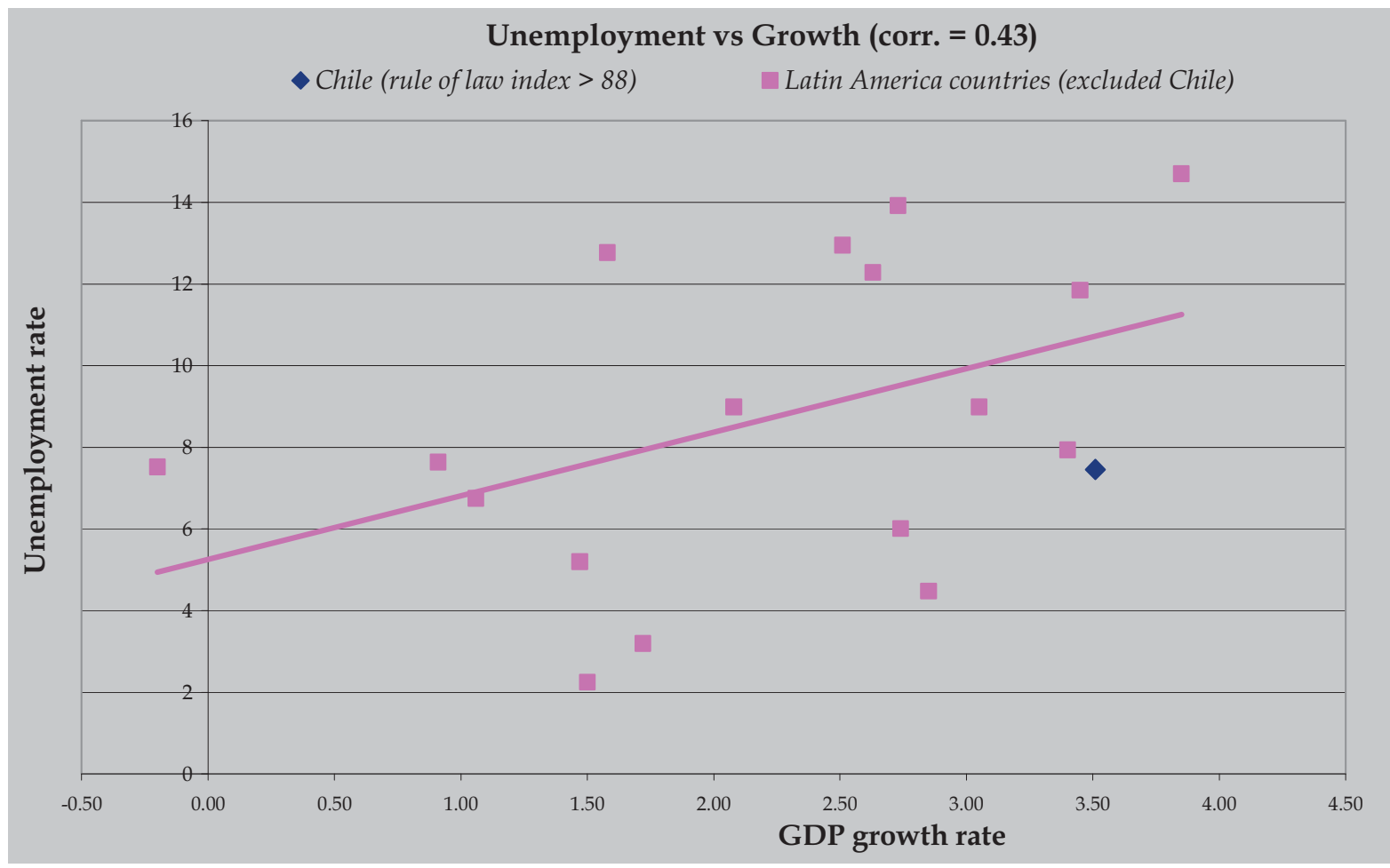


TABLE 1. Data for Figure 1

\begin{tabular}{cccc}
\hline $\begin{array}{c}\text { EU non-transition } \\
\text { countries }\end{array}$ & $\begin{array}{c}\text { unemployment rate } \\
\mathbf{( \% )} \boldsymbol{*}^{*}\end{array}$ & $\begin{array}{c}\text { GDP growth rate } \\
\mathbf{( \% )} \boldsymbol{*}^{*}\end{array}$ & $\begin{array}{c}\text { Rule of Law } \\
(\text { Percentile Rank } \\
* * *)\end{array}$ \\
\hline Austria & 3.73 & 2.29 & 99.0 \\
Belgium & 6.40 & 2.04 & 89.0 \\
Cyprus & 3.63 & 3.77 & 84.2 \\
Denmark & 3.88 & 1.56 & 99.5 \\
Finland & 6.76 & 3.21 & 97.6 \\
France & 7.44 & 1.90 & 90.0 \\
Germany & 8.51 & 1.47 & 93.3 \\
Greece & 7.98 & 3.98 & 73.2 \\
Ireland & 3.74 & 5.02 & 94.3 \\
Italy & 6.43 & 1.16 & 62.2 \\
Luxembourg & 3.06 & 4.27 & 96.2 \\
Malta & 4.69 & 1.80 & 91.4 \\
Netherlands & 2.88 & 2.16 & 94.7 \\
Portugal & 5.48 & 5.84 & 83.7 \\
Spain & 8.43 & 2.80 & 85.2 \\
Sweden & 4.92 & 4.71 & 98.1 \\
United Kingdom & 3.71 & 1.70 & 92.3
\end{tabular}

\begin{tabular}{cccc}
\hline EU transition countries & $\begin{array}{c}\text { unemployment rate } \\
(\mathbf{\%})\end{array}$ & $\begin{array}{c}\text { GDP growth rate } \\
(\mathbf{( \% )} *\end{array}$ & $\begin{array}{c}\text { Rule of Law ** } \\
(\text { Percentile Rank } \\
* * *)\end{array}$ \\
\hline Bulgaria & 10.94 & 5.59 & 51.2 \\
Czech Republic & 6.18 & 4.20 & 77.0 \\
Estonia & 7.86 & 7.02 & 84.7 \\
Hungary & 5.73 & 3.52 & 76.1 \\
Latvia & 8.91 & 7.32 & 71.3 \\
Lithuania & 9.47 & 6.97 & 67.5 \\
Poland & 13.11 & 1.32 & 65.1 \\
Romania & 5.46 & 5.70 & 53.6 \\
Slovakia & 13.52 & 4.32 & 67.0 \\
Slovenia & 4.92 & 3.31 & 82.3 \\
\hline
\end{tabular}

* (2000 - 2008) average.

Source: (http://epp.eurostat.ec.europa.eu/portal/page/portal/statistics/themes)

** Source: (http://info.worldbank.org/governance/wgi/mc_countries.asp)

*** Percentile rank, from 0 (worst) to 100 (best). Precisely, according to the World Bank, the 'Rule of Law' index measures the quality of contract enforcement, the police, and the courts, as well as the likelihood of crime and violence. 
TABLE 2. Data for Figure 2

\begin{tabular}{cccc}
\hline $\begin{array}{c}\text { Latin America } \\
\text { countries }\end{array}$ & $\begin{array}{c}\text { Unemployment } \\
\text { rate }\end{array}$ & $\begin{array}{c}\text { GDP growth } \\
\text { rate }\end{array}$ & $\begin{array}{c}\text { Rule of Law } \\
\text { index }\end{array}$ \\
\hline Argentina & 12.95 & 2.51 & 32.10 \\
Bolivia & 5.2 & 1.47 & 12.00 \\
Brazil & 8.99 & 2.08 & 46.40 \\
Chile & 7.46 & 3.51 & 88.00 \\
Colombia & 13.92 & 2.73 & 37.80 \\
Costa Rica & 6.01 & 2.74 & 62.70 \\
Dominican Republic & 14.7 & 3.85 & 33.00 \\
Ecuador & 8.99 & 3.05 & 9.10 \\
El Salvador & 6.75 & 1.06 & 30.60 \\
Guatemala & 2.25 & 1.50 & 12.90 \\
Honduras & 4.48 & 2.85 & 20.60 \\
Mexico & 3.2 & 1.72 & 29.70 \\
Nicaragua & 7.64 & 0.91 & 21.10 \\
Panama & 11.85 & 3.45 & 49.80 \\
Paraguay & 7.52 & -0.20 & 15.30 \\
Peru & 7.94 & 3.40 & 25.80 \\
Uruguay & 12.77 & 1.58 & 65.60 \\
Venezuela, R. B. de & 12.28 & 2.63 & 2.90 \\
\hline
\end{tabular}

* (\%) of labour force (2000-2008) average. Source: http:/ / data.worldbank.org/indicator/

** $(2000-2007)$ average.

Source: Alan Heston, Robert Summers and Bettina Aten, Penn World Table Version 6.3, Center for International Comparisons of Production, Income and Prices at the University of Pennsylvania, August 2009.

http://pwt.econ.upenn.edu/php_site/pwt_index.php

*** Source: (http://info.worldbank.org/governance/wgi/mc_countries.asp).

Percentile rank, from 0 (worst) to 100 (best). 


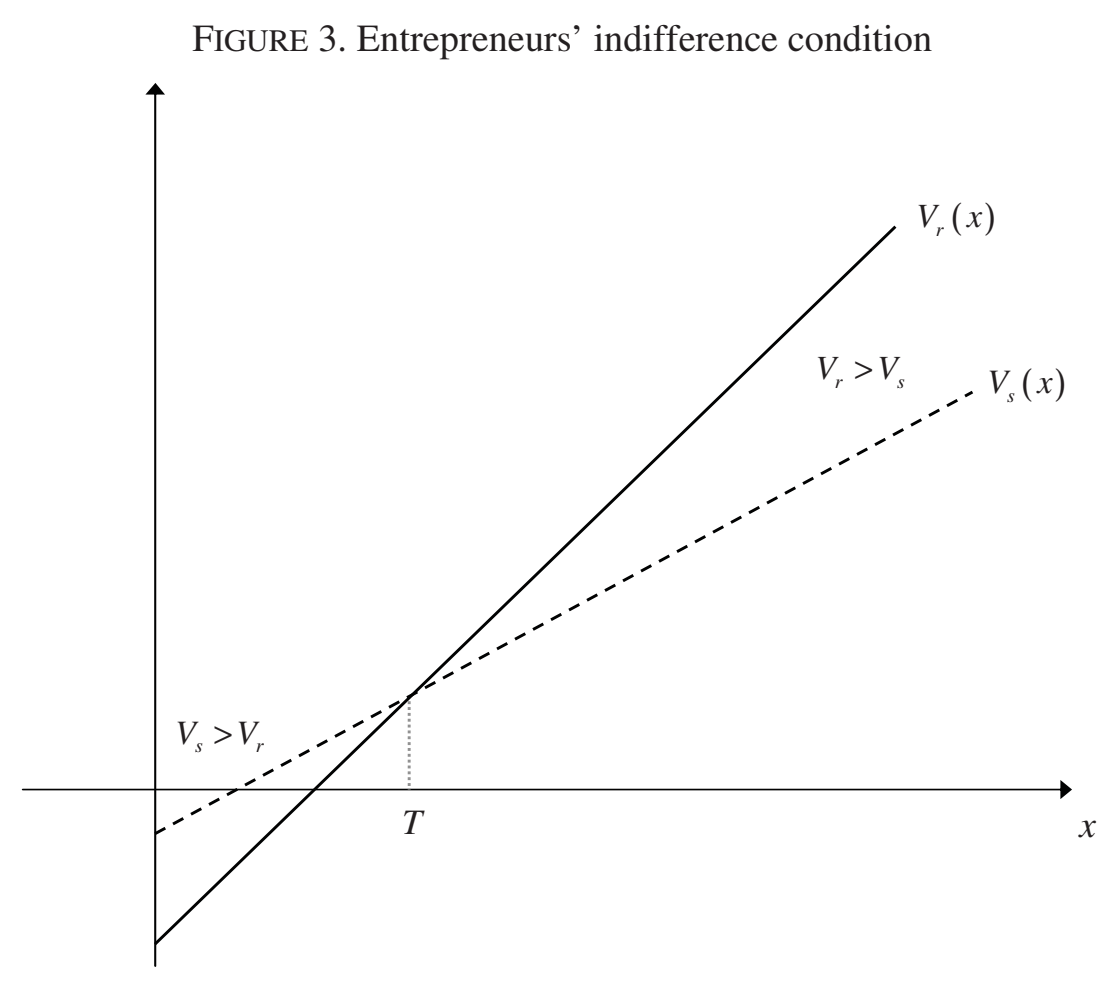

FIGURE 4. Interior equilibrium and multiple equilibria

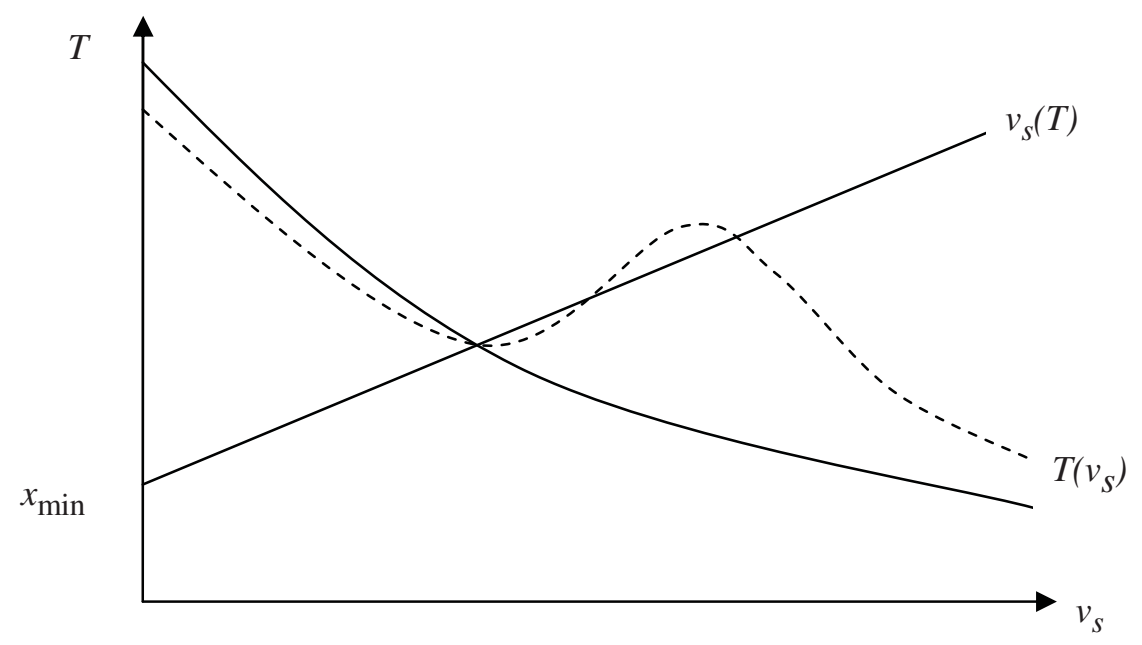

